\title{
Differences in lifestyle behaviors, dietary habits, and familial factors among normal-weight, overweight, and obese Chinese children and adolescents
}

\author{
Xiaofan Guo', Liqiang Zheng ${ }^{2}$, Yang Li ${ }^{1}$, Shasha Yu', Guozhe Sun'1, Hongmei Yang ${ }^{1}$, Xinghu Zhou',
} Xingang Zhang ${ }^{1}$, Zhaoqing Sun $^{3}$ and Yingxian Sun ${ }^{1 *}$

\begin{abstract}
Background: Pediatric obesity has become a global public health problem. Data on the lifestyle behaviors, dietary habits, and familial factors of overweight and obese children and adolescents are limited. The present study aims to compare health-related factors among normal-weight, overweight, and obese Chinese children and adolescents.

Methods: We conducted a cross-sectional study consisted of 4262 children and adolescents aged 5-18 years old from rural areas of the northeast China. Anthropometric measurements and self-reported information on health-related variables, such as physical activities, sleep duration, dietary habits, family income, and recognition of weight status from the views of both children and parents, were collected by trained personnel.

Results: The prevalence rates of overweight and obesity were 15.3 and 6.4\%, respectively. Compared to girls, boys were more commonly overweight (17.5\% vs. $12.9 \%)$ and obese (9.5\% vs. 3.1\%). Approximately half of the parents with an overweight or obese child reported that they failed to recognize their child's excess weight status, and 65\% of patients with an overweight child reported that they would not take measures to decrease their child's body weight. Obese children and adolescents were more likely to be nonsnackers [odds ratio (OR): 1.348; 95\% confidence interval (Cl): 1.039-1.748] and to have a family income of 2000 CNY or more per month (OR: 1.442; 95\% Cl: 1.045-1.99) and less likely to sleep longer ( $\geq 7.5 \mathrm{~h}$ ) (OR: $0.475 ; 95 \% \mathrm{Cl}: 0.31-0.728)$ than the normal-weight participants.
\end{abstract}

Conclusions: Our study revealed a high prevalence of overweight and obesity in a large Chinese pediatric population. Differences in sleep duration, snacking, family income, and parental recognition of children's weight status among participants in different weight categories were observed, which should be considered when planning prevention and treatment programs for pediatric obesity.

Keywords: Overweight, Obesity, Children, Adolescents, Health-related factors

\section{Background}

The worldwide prevalence of pediatric overweight and obesity has increased dramatically in recent years. It was reported that in 2010, 43 million children were estimated to be overweight and obese, and 92 million were at risk of becoming overweight. The worldwide prevalence of

\footnotetext{
* Correspondence: sunyingxian12@yahoo.com.cn

'Department of Cardiology, the First Hospital of China Medical University, 155 Nanjing North Street, Heping District, Shenyang 110001, People's Republic of China

Full list of author information is available at the end of the article
}

childhood overweight and obesity increased from $4.2 \%$ in 1990 to $6.7 \%$ in 2010 [1]. A high prevalence and increasing trend have been observed in many parts of the world [2-6]. In the most developed metropolis of China, the prevalence of overweight in children increased 2-3-fold between 1985 and 1995 [6]. Childhood obesity has become a global public health problem that has raised concern worldwide $[7,8]$.

The associated health risks and health care costs of childhood and adolescent obesity are considerable, the consequences of which include metabolic disorders,

\section{Ciomed Central}


earlier puberty and menarche in girls, type 2 diabetes, hypertension, sleep apnea, adulthood obesity, and higher rates of mortality in young adults [8-13]. Given the huge health burden resulting from pediatric overweight and obesity, efforts should be made to prevent the onset of overweight/obesity and its associated diseases during early childhood.

Overweight and obesity among children and adolescents are likely to be the result of complex interactions between genes, lifestyle behaviors, dietary habits, and socioeconomic factors. As the targets of many public health strategies, life-related factors are modifiable, and they have been highlighted in many investigations. It is evidenced that life-related factors, such as physical activity, eating habits, and family income, are associated with pediatric overweight and obesity $[7,8,14,15]$.

As the management of overweight/obesity among children and adolescents is often based on lifestyle modifications, recognition of the differences in lifestyle behaviors, dietary habits, or familial factors among children and adolescents with different weight status is the first step to take. However, the results of studies varied markedly due to differences in variables such as region and race. In rural areas of the northeast China, the health resources are relatively poor, the situation is often ignored by many health workers, and related data among children and adolescents, such as dietary habits and anthropological measurement results, are lacking. Therefore, we performed this study to measure 1) the prevalence of overweight and obesity in a large population sample of children and adolescents in the northeast China and 2) the differences in lifestyle behaviors, dietary habits, and familial factors in the participants with different weight status.

\section{Methods}

\section{Study population}

We conducted a cross-sectional study from July 2010 to January 2011 in rural areas of Shenyang, Liaoning Province, aiming to assess the differences in lifestyle behaviors, dietary habits, and familial factors among children and adolescents with different weight status. A total of 7637 students aged 5-18 years old were recruited. We adopted a multistage, stratified, cluster-sampling scheme and included participants from the northern, southern, western, and eastern regions of rural Shenyang. Three public schools were selected randomly from each geographic region. Samples from all of the classes in each school were included. In total, 12 public schools and 162 classes from these regions were selected. The overall response rate was $89 \%$. Students known to have chronic heart, renal, or hepatic disease were excluded. The final sample included 4262 students (2196 boys and 2066 girls). Figure 1 shows the process of recruitment and derivation of the

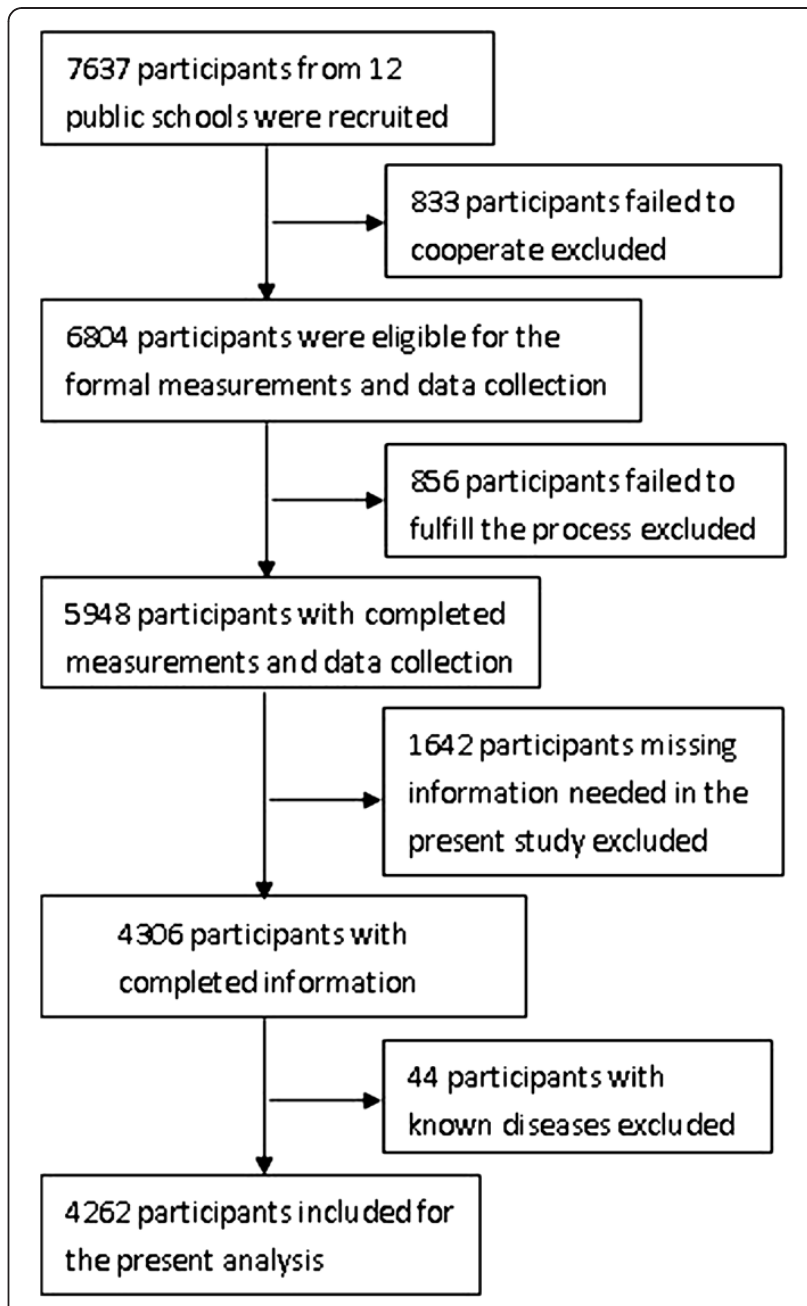

Figure 1 Flow chart of participant recruitment and derivation.

population. Informed consent was obtained from the parents of all subjects. The study was approved by the Ethics Committee of China Medical University.

\section{Data collection}

Information on personal characteristics, including age, gender, race, physical activities (e.g., jogging) and sedentary behaviors (e.g., watching television), transportation mode to school, sleep duration (including nocturnal sleep duration and nap duration), smoking and drinking status, parental education level, and family income, was collected by trained personnel (cardiologists, doctors of internal medicine, and pediatricians) using a questionnaire. The frequency of having breakfast and key food items (such as fresh fruit and vegetables) was evaluated. The possible responses were "never or occasionally," "less than once a week," "1-3 days per week," "4-6 days per week," and "everyday." The students were asked to rate their own level of weight status using the statements "too thin," "about right," "a little fat," or "too fat." Each participant 
was also asked to choose whether he/she would "put on weight," "lose weight," "stay the same as present," or "do nothing to his/her weight status" in the future. The same questions were answered by their parents to assess the parents' attitudes and any steps they to take regarding their children's weight status. The content validity of the questionnaire was assessed by specialists of the related field. Seven specialists were invited to evaluate the representativeness of each item against the aim of the questionnaire. A score for each item was required $(1=$ no correlation; 2 =weak correlation; $3=$ strong correlation; $4=$ extreme correlation). A high content validity index of 0.89 basing on the number of the specialists and their scores was observed, indicating a good content validity. Intraclass correlation coefficients were used to examine the test-retest agreement. Five hundred participants were selected randomly to complete the questionnaire a second time one month after the initial interview. The 1-month test-retest agreement for the questionnaire was 0.81 . Internal reliability was tested by Cronbach's alpha, and a value of 0.848 was obtained, indicating a good consistency of the questionnaire.

\section{Anthropometric measurements}

Blood pressure (BP) was measured by trained personnel using a mercury sphygmomanometer and an appropriately sized cuff after each subject had rested for at least $5 \mathrm{~min}$. The participants were advised to avoid coffee, tea, and exercise for at least $30 \mathrm{~min}$ before the measurement, and they remained seated with their arms supported at the level of the heart during the measurement. The average of two measurements was used in the analysis. With the subjects wearing light clothes without shoes, body weight was measured to the nearest $100 \mathrm{~g}$ by using a professional scale, and height was measured to the nearest $0.5 \mathrm{~cm}$ by using a stadiometer. Body mass index (BMI) was calculated using the formula weight $(\mathrm{kg}) /$ height $^{2}\left(\mathrm{~m}^{2}\right)$.

BP status was defined according to the Fourth Report on the Diagnosis, Evaluation, and Treatment of High Blood Pressure in Children and Adolescents [16]. Prehypertension was defined as a systolic BP (SBP) and/or diastolic BP (DBP) $\geq 90$ th percentile and $<95$ th percentile for age, gender and height, or alternatively, by an SBP of more than $120 \mathrm{mmHg}$ or a DBP of more than $80 \mathrm{mmHg}$. Hypertension was defined as an SBP and/or DBP $\geq 95$ th percentile. Weight class was defined according to the tables of the International Obesity Task Force based on data from the U.S., Brazil, The Netherlands, Hong Kong, United Kingdom, and Singapore [17].

\section{Statistical analysis}

Continuous variables were expressed as mean values and standard deviation (SD), whereas categorical variables were described as frequencies and percentages. Chisquare analyses were used to examine associations between the categorical variables and weight status. Continuous variables were compared between different weight status by using one-way analyses of variance. The association between overweight or obesity and healthrelated factors was tested using multivariable logistic regression models, with odds ratios (ORs) and 95\% confidence intervals (CIs) calculated. All statistical analyses were performed using SPSS version 17.0 software, and $P<0.05$ indicated statistical significance.

\section{Results}

The study sample consisted of 2196 boys and 2066 girls with a mean age of $11.04 \pm 2.7$ years. Of the 4262 participants, $15.3 \%$ were overweight, and $6.4 \%$ were obese. The prevalence of obesity was 9.5 and $3.1 \%$ among male and female participants, respectively. Overweight was found in 384 boys $(17.5 \%)$ and 267 girls (12.9\%). The prevalence of obesity decreased with age (5-8-year-olds: $7.6 \%$; 9-11-year-olds: 7.2\%; 12-14-year-olds: $5.9 \%$; 15-18year-olds: $3.1 \%$ ).

Figure 2 shows the median BMI by age and gender. The median BMI for boys was close to that of girls before the age of 15 . The median BMI among girls $\left(24.1 \mathrm{~kg} / \mathrm{m}^{2}\right)$ was higher than that of their male counterparts $\left(21.0 \mathrm{~kg} / \mathrm{m}^{2}\right)$ at the age of 17 . Figure 3 presents the prevalence of overweight plus obesity in different age groups by gender. Approximately one-third of boys and one-fifth of girls aged 5-11 years old had excess weight. Boys had higher prevalence than girls in all of the age categories.

Table 1 presents the baseline characteristics of the participants according to BMI categories. Boys had much higher proportions of overweight and obese participants. The Han Race predominated in all three weight classes.

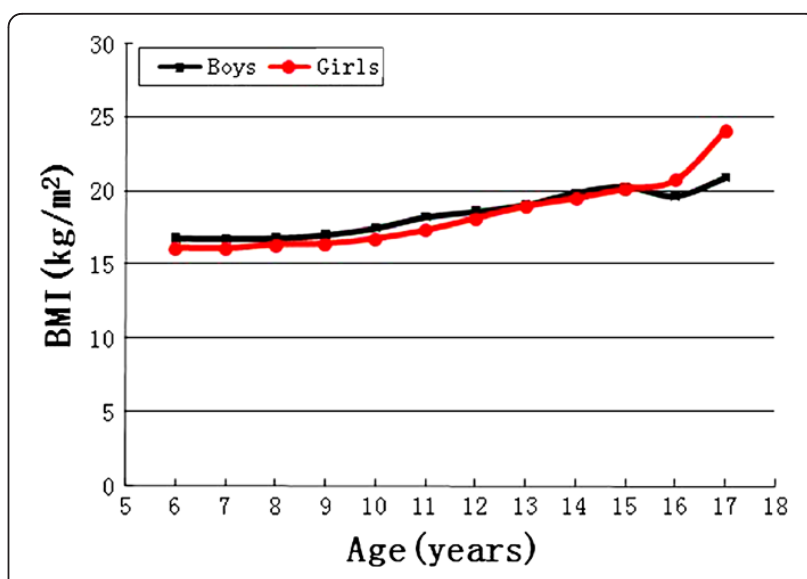

Figure 2 Median body mass index by age and gender. The $25^{\text {th }}$ and $75^{\text {th }}$ percentiles of BMI were 16.3 and $20.5 \mathrm{~kg} / \mathrm{m}^{2}$, respectively. 


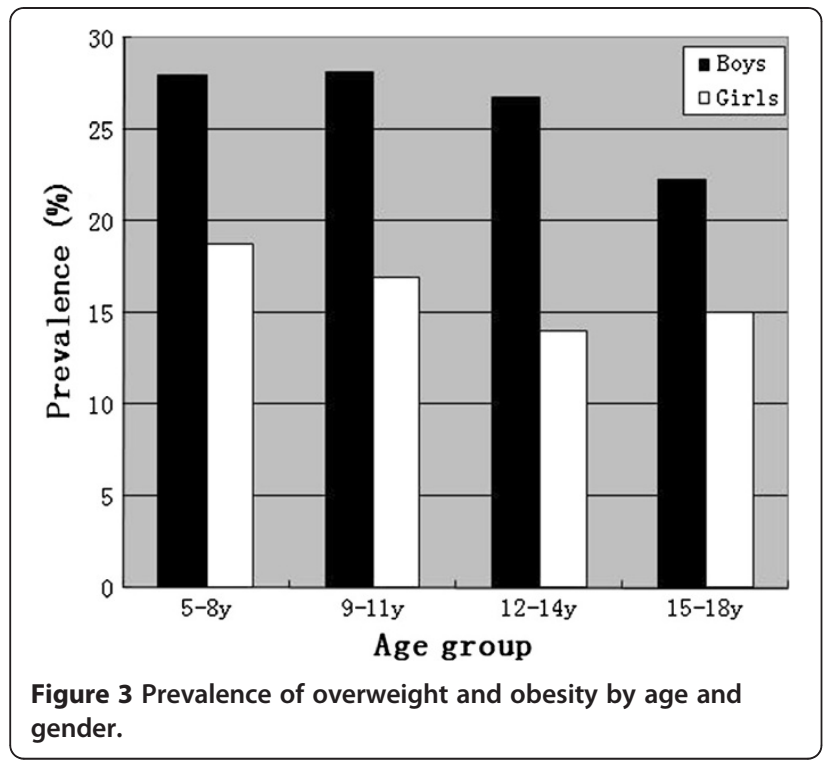

Hypertension was more common among overweight and obese participants than among those with normal BMI.

Tables 2, 3, 4 present the differences in life-related factors among normal-weight, overweight, and obese participants. More children and adolescents with normal weight self-reported the consumption of snacks $\geq 4$ days/ week compared to their obese counterparts $(22.7 \%$ vs. $16.5 \%, P<0.05)$. A higher self-reported family income ( $\geq 2000 \mathrm{CNY} /$ month) was more common among obese participants (82.1\%) than among those with normal weight (75.9\%). More overweight and obese participants were found to have a small family size (total member $\leq 3)$. No significant difference was observed in other selfreported variables such as sleep duration, physical activity, and the consumption of dietary products among the three weight categories.

Table 5 presents the recognition of weight status from the views of children and parents. Approximately onefifth of the obese children thought they were "about right" and would "stay the same as present." Among the parents of normal-weight children, $19.2 \%$ thought they were "too thin," and 19.7\% reported that they would take measures to increase the weight of their children. Approximately half of the parents with an overweight or obese child failed to recognize their child's excess weight status.

Table 6 presents the association between healthrelated factors and weight status according to multivariable logistic regression analysis. Overweight and obese participants were less likely to have a normal BP (OR: 0.437, 95\% CI: $0.366-0.522$ for overweight; OR: 0.206, 95\% CI: $0.157-0.269$ for obese). Obese children and

Table 1 Baseline characteristics of the participants by weight status $(\mathrm{N}=4262)$

\begin{tabular}{|c|c|c|c|c|c|}
\hline & Normal $(n=3338)$ & Overweight $(n=651)$ & Obese $(n=273)$ & Total $(\mathrm{N}=4262)$ & $P$-value \\
\hline Gender & & & & & $<0.001^{*}$ \\
\hline Boys & 1603(48) & $384(59)$ & 209(76.6) & 2196(51.5) & \\
\hline Girls & 1735(52) & $267(41)$ & $64(23.4)$ & 2066(48.5) & \\
\hline Age & & & & & $0.035^{*}$ \\
\hline $5-8 y$ & $676(20.3)$ & $140(21.5)$ & $67(24.5)$ & $883(20.7)$ & \\
\hline $9-11 y$ & $1148(34.4)$ & $231(35.5)$ & 107(39.2) & 1486(34.9) & \\
\hline $12-14 y$ & $1152(34.5)$ & $211(32.4)$ & $85(31.1)$ & 1448(34) & \\
\hline $15-18 y$ & $362(10.8)$ & $69(10.6)$ & $14(5.1)$ & $445(10.4)$ & \\
\hline Race & & & & & 0.197 \\
\hline Han & $2762(82.7)$ & $524(80.5)$ & $212(77.7)$ & $3498(82.1)$ & \\
\hline Manchu & $323(9.7)$ & $75(11.5)$ & $37(13.6)$ & $435(10.2)$ & \\
\hline Mongol & $122(3.7)$ & $26(4)$ & $15(5.5)$ & 163(3.8) & \\
\hline Others & $131(3.9)$ & $26(4)$ & $9(3.3)$ & $166(3.9)$ & \\
\hline Weight(kg) & $37.11 \pm 10.8$ & $49.18 \pm 14.63$ & $60.66 \pm 18.44$ & $40.46 \pm 13.86$ & $<0.001^{*}$ \\
\hline Height(cm) & $143.79 \pm 14.77$ & $145.88 \pm 15.1$ & $146.52 \pm 16$ & $144.28 \pm 14.93$ & $<0.001^{*}$ \\
\hline $\operatorname{BMI}\left(\mathbf{k g} / \mathrm{m}^{2}\right)$ & $17.5 \pm 2.1$ & $22.4 \pm 2.6$ & $27.5 \pm 3.9$ & $18.9 \pm 3.7$ & $<0.001^{*}$ \\
\hline BP status & & & & & $<0.001^{*}$ \\
\hline Normal & 2304(69) & $335(51.5)$ & $99(36.3)$ & $2738(64.2)$ & \\
\hline Prehypertension & 492(14.7) & 116(17.8) & $44(16.1)$ & $652(15.3)$ & \\
\hline Hypertension & $542(16.2)$ & $200(30.7)$ & 130(47.6) & $872(20.5)$ & \\
\hline
\end{tabular}

Data are expressed as $\mathrm{n}(\%)$ or as the mean \pm SD. BMI: body mass index; BP: blood pressure.

${ }^{*} \mathrm{P}<0.05$, statistically significant difference. 
Table 2 Differences in lifestyle behaviours among the participants with different weight status

\begin{tabular}{|c|c|c|c|c|c|}
\hline & \multirow{2}{*}{$\begin{array}{c}\text { Normal } \\
(n=3338)\end{array}$} & \multirow{2}{*}{$\begin{array}{l}\text { Overweight } \\
(n=651)\end{array}$} & \multirow{2}{*}{$\begin{array}{c}\text { Obese } \\
(n=273)\end{array}$} & \multicolumn{2}{|c|}{$P$-value } \\
\hline & & & & Overweight vs. normal & Obesity vs. normal \\
\hline Sleep duration(h/day) & & & & 0.169 & 0.089 \\
\hline$<8$ & $370(11.1)$ & $62(9.5)$ & $37(13.6)$ & & \\
\hline $8-9$ & 1104(33.1) & 238(36.6) & 102(37.4) & & \\
\hline$\geq 9$ & 1864(55.8) & $351(53.9)$ & 134(49.1) & & \\
\hline Physical activity(times/week) & & & & 0.34 & 0.215 \\
\hline None & $91(2.7)$ & $17(2.6)$ & $4(1.5)$ & & \\
\hline 1 to 3 & $1774(53.1)$ & $331(50.8)$ & $140(51.3)$ & & \\
\hline$>3$ & 1473(44.1) & $303(46.5)$ & 129(47.3) & & \\
\hline Watching TV $\geq 3 \mathrm{~h} /$ day & $617(18.5)$ & 116(17.8) & $61(22.3)$ & 0.688 & 0.116 \\
\hline \multicolumn{6}{|c|}{ Playing video games and using computers $\geq 3 \mathrm{~h} /$ day } \\
\hline & $220(6.6)$ & $43(6.6)$ & $14(5.1)$ & 0.989 & 0.345 \\
\hline Walking to school & 1780(53.3) & $346(53.1)$ & 134(49.1) & 0.934 & 0.177 \\
\hline Nonsmoking & $2880(86.3)$ & $553(84.9)$ & $224(82.1)$ & 0.369 & 0.053 \\
\hline No alcohol use & $2810(84.2)$ & $545(83.7)$ & 223(81.7) & 0.767 & 0.279 \\
\hline
\end{tabular}

Data are expressed as $\mathrm{n}(\%)$.

adolescents were more likely to never or occasionally have snacks (OR: 1.348, 95\% CI: 1.039-1.748) and to have a family income of $2000 \mathrm{CNY}$ or more per month (OR: 1.442, 95\% CI: 1.045-1.99) than those with normal weight. Normal-weight participants were significantly more likely to have long sleep duration than the obese participants and less likely to have a small family size than the overweight participants.

\section{Discussion}

A large sample of the Chinese population was studied to explore current lifestyle health behaviors among children and adolescents. Overweight and obesity were found to be highly prevalent, particularly among the male participants. Differences in health-related factors and the recognition of weight status among participants in different weight categories were observed. Obese children were more likely to be nonsnackers, to have a shorter sleep duration, and to have a higher family income.

The high prevalence of overweight/obesity in this study was in line with many other studies [5,18-20]. It was reported that the prevalence of adolescent obesity increased dramatically from 5 to $13 \%$ in boys and from 5 to $9 \%$ in girls between 1966-70 and 1988-91 in the U.S. [21]. Data from China also indicated that the prevalence of overweight and obesity among 7-9-year-olds increased from approximately $1-2 \%$ in 1985 to $17 \%$ among girls and 25\% among boys in 2000 in big cities [22]. The time trend of this rapidly growing epidemic was observed in both developed and developing

Table 3 Differences in dietary characteristics among the participants with different weight status

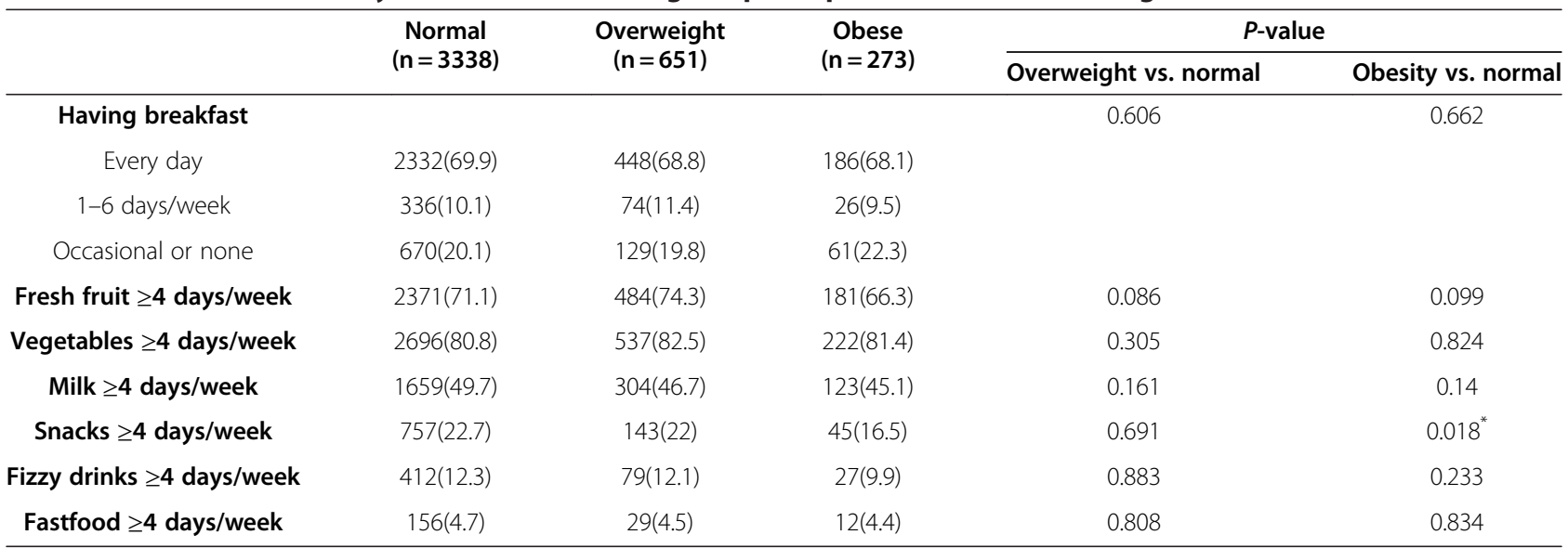

Data are expressed as $\mathrm{n}(\%) .{ }^{*} \mathrm{P}<0.05$, statistically significant difference. 
Table 4 Differences in familial factors among the participants with different weight status

\begin{tabular}{|c|c|c|c|c|c|}
\hline & Normal & Overweight & Obese & $P-\mathrm{v}$ & \\
\hline & $(n=3338)$ & & & Overweight vs. normal & Obesity vs. normal \\
\hline Family income $\geq 2000 \mathrm{CNY} /$ month & 2535(75.9) & $500(76.8)$ & 224(82.1) & 0.637 & $0.022^{*}$ \\
\hline Family size $\leq 3$ & $1806(54.1)$ & $396(60.8)$ & $165(60.4)$ & $0.002^{*}$ & $0.043^{*}$ \\
\hline Smoking mother & $230(6.9)$ & $35(5.4)$ & 19(7) & 0.156 & 0.965 \\
\hline Smoking father & $1705(51.1)$ & $352(54.1)$ & $152(55.7)$ & 0.162 & 0.144 \\
\hline Educational level of parents & & & & 0.139 & 0.337 \\
\hline Both $\leq$ high school & 2974(89.1) & $568(87.3)$ & 240(87.9) & & \\
\hline At least one $>$ high school & $189(5.7)$ & $50(7.7)$ & $21(7.7)$ & & \\
\hline Both $>$ high school & $175(5.2)$ & $33(5.1)$ & $12(4.4)$ & & \\
\hline Unemployed mother & $605(18.1)$ & 109(16.7) & $50(18.3)$ & 0.4 & 0.937 \\
\hline Unemployed father & $283(8.5)$ & $54(8.3)$ & $23(8.4)$ & 0.878 & 0.976 \\
\hline
\end{tabular}

Data are expressed as $n(\%) .{ }^{*} \mathrm{P}<0.05$, statistically significant difference. CNY: China Yuan. $1 \mathrm{CNY}=0.157$ USD.

countries [2-6,23]. Given its huge impact on future generations, great attention should be paid to establishing appropriate prevention and treatment programs.

In the present study, we found that obese participants were more likely to be nonsnackers compared to the normal-weight ones. Several studies have investigated the association between snacking and pediatric obesity, the results of which were conflicting. Some studies suggested that snacking might increase energy intake and thus promote weight gain $[24,25]$, whereas others reported an inverse relationship between snacking and body weight [26-28]. The negative association found in

Table 5 Differences in recognitions from children and parents towards the weight status

\begin{tabular}{|c|c|c|c|c|c|}
\hline & \multirow{2}{*}{$\begin{array}{c}\text { Normal } \\
(n=3338)\end{array}$} & \multirow{2}{*}{$\begin{array}{c}\text { Overweight } \\
(n=651)\end{array}$} & \multirow{2}{*}{$\begin{array}{c}\text { Obese } \\
(n=273)\end{array}$} & \multicolumn{2}{|c|}{$P$-value } \\
\hline & & & & Overweight vs. normal & Obesity vs. normal \\
\hline \multicolumn{6}{|l|}{ Children } \\
\hline Attitude towards their weight status & & & & $<0.001$ & $<0.001$ \\
\hline Too thin & $444(13.3)$ & $11(1.7)$ & $4(1.5)$ & & \\
\hline About right & $2361(70.7)$ & 235(36.1) & $45(16.5)$ & & \\
\hline A little fat & 497(14.9) & $333(51.2)$ & 137(50.2) & & \\
\hline Too fat & $36(1.1)$ & $72(11.1)$ & $87(31.9)$ & & \\
\hline What will do to their weight status & & & & $<0.001$ & $<0.001$ \\
\hline should put on weight & $508(15.2)$ & 20(3.1) & $3(1.1)$ & & \\
\hline should lose weight & $418(12.5)$ & $303(46.5)$ & 189(69.2) & & \\
\hline stay the same as present & $1827(54.7)$ & 223(34.3) & $49(17.9)$ & & \\
\hline no measures & $585(17.5)$ & 105(16.1) & $32(11.7)$ & & \\
\hline \multicolumn{6}{|l|}{ Parents } \\
\hline Attitude towards their weight status & & & & $<0.001$ & $<0.001$ \\
\hline Too thin & $641(19.2)$ & 20(3.1) & $7(2.6)$ & & \\
\hline About right & $2350(70.4)$ & $262(40.2)$ & $36(13.2)$ & & \\
\hline A little fat & $321(9.6)$ & $296(45.5)$ & $120(44)$ & & \\
\hline Too fat & $26(0.8)$ & $73(11.2)$ & $110(40.3)$ & & \\
\hline What will do to children's weight status & & & & $<0.001$ & $<0.001$ \\
\hline should put on weight & 656(19.7) & $29(4.5)$ & $7(2.6)$ & & \\
\hline should lose weight & $217(6.5)$ & 235(36.1) & $181(66.3)$ & & \\
\hline stay the same as present & $1709(51.2)$ & 246(37.8) & 43(15.8) & & \\
\hline no measures & $756(22.6)$ & $141(21.7)$ & $42(15.4)$ & & \\
\hline
\end{tabular}

Data are expressed as $n(\%)$. 
Table 6 Association between weight status and health-related factors

\begin{tabular}{|c|c|c|c|c|c|c|c|}
\hline & \multirow{2}{*}{$\frac{\text { Normal }}{\text { OR (referent) }}$} & \multicolumn{3}{|c|}{ Overweight } & \multicolumn{3}{|c|}{ Obese } \\
\hline & & OR & $95 \% \mathrm{Cl}$ & $P$-value & OR & $95 \% \mathrm{Cl}$ & $P$-value \\
\hline Normal BP & 1 & 0.437 & $0.366-0.522$ & $<0.001^{*}$ & 0.206 & $0.157-0.269$ & $<0.001^{*}$ \\
\hline Sleep duration $\geq 7.5 \mathrm{~h}$ & 1 & 1.065 & $0.77-1.472$ & 0.704 & 0.475 & $0.31-0.728$ & $0.001^{*}$ \\
\hline Physical activity $>3$ times/week & 1 & 1.098 & $0.927-1.3$ & 0.28 & 1.12 & $0.872-1.438$ & 0.375 \\
\hline Watching TV $\geq 3$ h/day & 1 & 0.93 & $0.747-1.159$ & 0.521 & 1.191 & $0.881-1.611$ & 0.256 \\
\hline Playing video games and using computers $\geq 3 \mathrm{~h} /$ day & 1 & 0.963 & $0.685-1.353$ & 0.828 & 0.699 & $0.399-1.224$ & 0.211 \\
\hline Walking to school & 1 & 0.996 & $0.842-1.18$ & 0.966 & 0.852 & $0.664-1.094$ & 0.21 \\
\hline Nonsmoking & 1 & 0.915 & $0.721-1.161$ & 0.463 & 0.774 & $0.556-1.076$ & 0.127 \\
\hline No alcohol use & 1 & 0.996 & $0.791-1.253$ & 0.97 & 0.921 & $0.664-1.275$ & 0.619 \\
\hline Never or occasionally have snacks & 1 & 1.074 & $0.904-1.276$ & 0.418 & 1.348 & $1.039-1.748$ & $0.025^{*}$ \\
\hline Breakfast every day & 1 & 0.945 & $0.785-1.138$ & 0.552 & 0.879 & $0.669-1.156$ & 0.357 \\
\hline Fresh fruit $\geq 4$ days/week & 1 & 1.202 & $0.991-1.457$ & 0.061 & 0.831 & $0.637-1.084$ & 0.172 \\
\hline Vegetables $\geq 4$ days/week & 1 & 1.145 & $0.918-1.428$ & 0.229 & 1.099 & $0.798-1.153$ & 0.564 \\
\hline Milk $\geq 4$ days/week & 1 & 0.886 & $0.748-1.05$ & 0.162 & 0.823 & $0.64-1.059$ & 0.13 \\
\hline Fizzy drinks $\geq 4$ days/week & 1 & 0.983 & $0.758-1.274$ & 0.894 & 0.802 & $0.528-1.216$ & 0.298 \\
\hline Fastfood $\geq 4$ days/week & 1 & 0.941 & $0.626-1.413$ & 0.768 & 0.919 & $0.501-1.686$ & 0.784 \\
\hline Family income $\geq 2000 \mathrm{CNY} /$ month & 1 & 1.045 & $0.856-1.275$ & 0.666 & 1.442 & $1.045-1.99$ & $0.026^{*}$ \\
\hline Family size $\leq 3$ & 1 & 1.26 & $1.06-1.497$ & $0.009^{*}$ & 1.144 & $0.886-1.477$ & 0.302 \\
\hline Education of both parents above high school & 1 & 0.943 & $0.641-1.385$ & 0.764 & 0.774 & $0.422-1.418$ & 0.406 \\
\hline Smoking mother & 1 & 0.776 & $0.538-1.121$ & 0.177 & 1.049 & $0.641-1.714$ & 0.85 \\
\hline Smoking father & 1 & 1.124 & $0.949-1.332$ & 0.176 & 1.205 & $0.937-1.55$ & 0.146 \\
\hline Unemployed mother & 1 & 0.904 & $0.721-1.132$ & 0.379 & 0.995 & $0.72-1.376$ & 0.978 \\
\hline Unemployed father & 1 & 0.963 & $0.71-1.307$ & 0.81 & 0.954 & $0.609-1.495$ & 0.837 \\
\hline
\end{tabular}

Adjusted for age, gender and race. ${ }^{*} \mathrm{P}<0.05$, statistically significant difference.

BP: blood pressure; OR: odds ratio; 95\% Cl: 95\% confidence interval. CNY: China Yuan. 1 CNY $=0.157$ USD.

our study may be explained by the composition of snacks and the compensation of the energy from snacks. Summerbell et al found that snack foods, compared with meals, are actually lower in fat and higher in carbohydrates [29]. It was also evidenced that among night snackers, eating cereal after the evening meal could reduce caloric intake and promote weight loss [30], indicating the important role of reasonable snack composition. In a study of snack consumption for 8 weeks, no weight gain was observed regardless of the moment of consumption and energy density of snacks [31]. This could be explained by the association between snacking and increased vigorous physical activity [26] or by rapid physical development in this period. The increased energy intake from snacking may have been compensated by activity or growth, thus limiting the development of obesity.

A substantial amount of evidence exists regarding the link between short sleep duration and childhood and adolescent overweight or obesity $[28,32,33]$. A metaanalysis including 36 publications found that short sleep duration was independently associated with weight gain, particularly in younger age groups [34]. The present study indicated that childhood and adolescent obesity was associated with a shorter sleep duration $(<7.5 \mathrm{~h})$, confirming the earlier findings. The mechanisms underlying are not fully understood. Upregulation of appetite, alterations in glucose metabolism, and decreased energy expenditure might be the potential reasons for these findings $[35,36]$.

In our study, we found that approximately half of the parents with an overweight or obese child failed to recognize their child's excess weight status. Approximately $35 \%$ of the parents with an obese child and $65 \%$ with an overweight child would not take measures to decrease their child's body weight. The low rate of parental recognition of childhood overweight and obesity in this study is consistent with other studies [37-39]. This phenomenon might be due to exaggerated parental concern regarding their children. They continued to feed their babies because of worries about insufficient nutrition and energy for their children. In some cultures, big children are viewed more positively as "cute and healthy" [40], which also contributed to this situation. In 
addition, low recognition of excess weight status among children and adolescents was observed. These findings should be considered when planning prevention and treatment programs of pediatric obesity.

Regarding family income, Wang et al found that among children aged 6-18 years old, those in higher income groups were more likely to be obese in China and Russia, whereas those in lower income groups were at a higher risk of being obese in the U.S. [41]. Our study indicated that obese participants were more likely to have a higher family income, similar to the result found in a Jordanian population [42] and contrary to the result in Canadian children [43]. The mechanism of this region-related difference requires more exploration.

Although many studies have reported that some health-related factors, such as skipping breakfast, physical inactivity, and long hours of TV watching and video game playing, were associated with childhood and adolescent obesity $[28,42,44,45]$, we failed to find statistically significant results, possibly due to the different definitions of the variables and an insufficient sample size.

There are limitations in the present study. First, our data were obtained from a cross-sectional study in rural Northeast China and are not representative of children and adolescents throughout the whole country. Extrapolating the conclusions to the general population should be done cautiously. Second, these analyses rely on self-reports from children and their parents, which might compromise the accuracy. Third, a relatively high drop of our population was observed. Although there were no significant differences in age and gender between the retained and excluded populations, this might still compromise the representativeness and the precision of the results. In addition, our results are based on a cross-sectional design, and thus, we could not define a causal association between health-related factors and weight status.

\section{Conclusions}

In summary, the prevalence of pediatric overweight and obesity was relatively high, particularly among the male participants. Differences in health-related factors and the parental recognition of their children' weight status among participants with different weight categories were observed. Obese children were more likely to be nonsnackers and to have a shorter sleep duration and higher family income. Collective evaluation of multiple healthrelated factors should receive more attention to better prevent and control overweight and obesity in this segment of the population.

\section{Abbreviations}

BMI: Body mass index; BP: Blood pressure; SBP: Systolic BP; DBP: Diastolic BP; SD: Standard deviation; OR: Odds ratio; Cl: Confidence interval; CNY: China Yuan.

\section{Competing interests}

The authors declare that they have no competing interests.

\section{Authors' contributions}

XF Guo, LQ Zheng and Y Li participated in the protocol development, data analysis and writing of the manuscript. SS Yu, GZ Sun, HM Yang, XH Zhou and $X G$ Zhang participated in the development of the protocol, anthropometric measurement and data collection. ZX Sun and YX Sun supervised the design and execution of the study and contributed to the revision of the manuscript. All authors read and approved the final manuscript.

\section{Acknowledgements}

This study was supported by grants from the Special Program for National Key Basic Research and Development Prorgram (2010CB535011).

\section{Author details}

'Department of Cardiology, the First Hospital of China Medical University, 155 Nanjing North Street, Heping District, Shenyang 110001, People's Republic of China. ${ }^{2}$ Department of Clinical epidemiology, Library, Shengjing Hospital of China Medical University, Shenyang, People's Republic of China. ${ }^{3}$ Department of Cardiology, Shengjing Hospital of China Medical University, Shenyang, People's Republic of China.

Received: 23 October 2011 Accepted: 25 September 2012 Published: 2 October 2012

\section{References}

1. de Onis M, Blössner M, Borghi E: Global prevalence and trends of overweight and obesity among preschool children. Am J Clin Nutr 2010, 92(5):1257-1264.

2. Kautiainen S, Rimpelä A, Vikat A, Virtanen SM: Secular trends in overweight and obesity among Finnish adolescents in 1977-1999. Int J Obes Relat Metab Disord 2002, 26(4):544-552.

3. Sanigorski AM, Bell AC, Kremer PJ, Swinburn BA: High childhood obesity in an Australian population. Obesity (Silver Spring) 2007, 15(8):1908-1912.

4. Stamatakis E, Wardle J, Cole TJ: Childhood obesity and overweight prevalence trends in England: evidence for growing socioeconomic disparities. Int J Obes (Lond) 2010, 34(1):41-47.

5. Malik M, Bakir A: Prevalence of overweight and obesity among children in the United Arab Emirates. Obes Rev 2007, 8(1):15-20.

6. Ji CY, Sun JL, Chen TJ: Dynamic analysis on the prevalence of obesity and overweight school-age children and adolescents in recent 15 years in China. Zhonghua Liu Xing Bing Xue Za Zhi 2004, 25(2):103-108.

7. Franco M, Sanz B, Otero L, Domínguez-Vila A, Caballero B: Prevention of childhood obesity in Spain: a focus on policies outside the health sector. SESPAS report 2010. Gac Sanit 2010, 24(Suppl 1):49-55.

8. Zheng L, Sun Z, Zhang X, Xu C, Li J, Hu D, Sun Y: Predictors of progression from prehypertension to hypertension among rural Chinese adults: results from Liaoning Province. Eur J Cardiovasc Prev Rehabil 2010, 17(2):217-222.

9. Weiss R, Dziura J, Burgert TS, Tamborlane W, Taksali SE, Yeckel CW, Allen K, Lopes M, Savoye M, Morrison J, Sherwin RS, Caprio S: Obesity and the metabolic syndrome in children and adolescents. N Engl J Med 2004 350:2362-2374.

10. Biro FM, Huang B, Morrison JA, Horn PS, Daniels SR: Body mass index and waist-to-height changes during teen years in girls are influenced by childhood body mass index. J Adolesc Health 2010, 46:245-250.

11. Arens R, Muzumdar $\mathrm{H}$ : Childhood obesity and obstructive sleep apnea syndrome. J Appl Physiol 2010, 108(2):436-444.

12. Engeland A, Bjorge T, Tverdal A, Sogaard AJ: Obesity in adolescence and adulthood and the risk of adult mortality. Epidemiology 2004, 15:79-85.

13. Wabitsch M: Overweight and obesity in European children: definition and diagnostic procedures, risk factors and consequences for later health outcome. Eur J Pediatr 2000, 159(suppl 1):S8-S13.

14. Janssen I, Katzmarzyk PT, Boyce WF, King MA, Pickett W: Overweight and obesity in Canadian adolescents and their associations with dietary habits and physical activity patterns. J Adolesc Health 2004, 35(5):360-367.

15. Han JC, Lawlor DA, Kimm SY: Childhood obesity. Lancet 2010, 375 (9727):1737-1748. 
16. National High Blood Pressure Education Program Working Group on High Blood Pressure in Children and Adolescents: The fourth report on the diagnosis, evaluation, and treatment of high blood pressure in children and adolescents. Pediatrics 2004, 114:555-576.

17. Cole TJ, Bellizzi MC, Flegal KM, Dietz WH: Establishing a standard definition for child overweight and obesity worldwide: international survey. $B M J$ 2000, 320(7244):1240-1243.

18. Mushtaq MU, Gull S, Abdullah HM, Shahid U, Shad MA, Akram J: Prevalence and socioeconomic correlates of overweight and obesity among Pakistani primary school children. BMC Publ Health 2011, 11:724.

19. Velluzzi F, Lai A, Secci G, Mastinu R, Pilleri A, Cabula R, Rizzolo E, Cocco PL, Fadda D, Binaghi F, Mariotti S, Loviselli A: Prevalence of overweight and obesity in Sardinian adolescents. Eat Weight Disord 2007, 12(2):e44-e50.

20. Ferreira RJ, Marques-Vidal PM: Prevalence and determinants of obesity in children in public schools of Sintra, Portugal. Obesity (Silver Spring) 2008, 16(2):497-500.

21. Kosti Rl, Panagiotakos DB: The epidemic of obesity in children and adolescents in the world. Cent Eur J Public Health 2006, 14(4):151-159.

22. Wang L, Kong L, Wu F, Bai Y, Burton R: Preventing chronic diseases in China. Lancet 2005, 366:1821-1824.

23. Raj M, Sundaram KR, Paul M, Deepa AS, Kumar RK: Obesity in Indian children: time trends and relationship with hypertension. Natl Med J India 2007, 20:288-293.

24. Bertéus Forslund H, Torgerson JS, Sjostrom L, Lindroos AK: Snacking frequency in relation to energy intake and food choices in obese men and women compared to a reference population. Int J Obes (Lond) 2005 29(6):711-719.

25. Jahns L, Siega-Riz AM, Popkin BM: The increasing prevalence of snacking among US children from 1977 to 1996. J Pediatr 2001, 138(4):493-498.

26. Keast DR, Nicklas TA, O'Neil CE: Snacking is associated with reduced risk of overweight and reduced abdominal obesity in adolescents: National Health and Nutrition Examination Survey (NHANES) 1999-2004. Am J Clin Nutr 2010, 92(2):428-435

27. Phillips SM, Bandini LG, Naumova EN, Cyr H, Colclough S, Dietz WH, Must A: Energy-dense snack food intake in adolescence: Longitudinal relationship to weight and fatness. Obes Res 2004, 12(3):461-472.

28. Sun Y, Sekine M, Kagamimori S: Lifestyle and overweight among Japanese adolescents: the Toyama Birth Cohort Study. J Epidemio/ 2009, 19(6):303-310.

29. Summerbell CD, Moody RC, Shanks J, Stock MJ, Geissler C: Sources of energy from meals versus snacks in 220 people in four age groups. Eur $J$ Clin Nutr 1995, 49:33-41.

30. Waller SM, Vander Wal JS, Klurfeld DM, McBurney MI, Cho S, Bijlani S, Dhurandhar NV: Evening ready-to-eat cereal consumption contributes to weight management. J Am Coll Nutr 2004, 23(4):316-321.

31. Viskaal-van Dongen $M$, Kok FJ, de Graaf C: Effects of snack consumption for 8 weeks on energy intake and body weight. Int J Obes (Lond) 2010, 34(2):319-326

32. Yu Y, Lu BS, Wang B, Wang H, Yang J, Li Z, Wang L, Liu X, Tang G, Xing H, Xu X, Zee PC, Wang X: Short sleep duration and adiposity in Chinese adolescents. Sleep 2007, 30(12):1688-1697.

33. Shaikh WA, Patel M, Singh S: Sleep deprivation predisposes gujarati Indian adolescents to obesity. Indian J Community Med 2009, 34(3):192-194.

34. Patel SR, Hu FB: Short sleep duration and weight gain: a systematic review. Obesity (Silver Spring) 2008, 16(3):643-653.

35. Knutson KL, Spiegel K, Penev $\mathrm{P}$, Van Cauter $\mathrm{E}$ : The metabolic consequences of sleep deprivation. Sleep Med Rev 2007, 11:163-178.

36. Knutson KL: Sleep duration and cardiometabolic risk: a review of the epidemiologic evidence. Best Pract Res Clin Endocrinol Metab 2010, 24(5):731-743.

37. Parry LL, Netuveli G, Parry J, Saxena S: A systematic review of parental perception of overweight status in children. J Ambul Care Manage 2008, 31:253-268.

38. Vuorela N, Saha MT, Salo MK: Parents underestimate their child’s overweight. Acta Paediatr 2010, 99:1374-1379.

39. Eckstein KC, Mikhail LM, Ariza AJ, Thomson JS, Millard SC, Binns HJ, Pediatric Practice Research Group: Parents' perceptions of their child's weight and health. Pediatrics 2006, 117:681-690.

40. Adams AK, Quinn RA, Prince RJ: Low recognition of childhood overweight and disease risk among Native-American caregivers. Obes Res 2005, 13:146-152.
41. Wang Y: Cross-national comparison of childhood obesity: The epidemic and the relationship between obesity and socioeconomic status. International Journal of Epidemiology 2001, 30(5):1129-1136.

42. Khader $Y$, Irshaidat $O$, Khasawneh M, Amarin Z, Alomari M, Batieha A Overweight and obesity among school children in Jordan: prevalence and associated factors. Matern Child Health J 2009, 13(3):424-431.

43. Phipps SA, Burton PS, Osberg LS, Lethbridge LN: Poverty and the extent of child obesity in Canada, Norway and the United States. Obes Rev 2006, 7(1):5-12.

44. Burke V, Beilin LJ, Durkin K, Stritzke WG, Houghton S, Cameron CA: Television, computer use, physical activity, diet and fatness in Australian adolescents. Int J Pediatr Obes 2006, 1(4):248-255.

45. Mahfouz AA, Shatoor AS, Khan MY, Daffalla AA, Mostafa OA, Hassanein MA Nutrition, physical activity, and gender risks for adolescent obesity in Southwestern Saudi Arabia. Saudi J Gastroenterol 2011, 17(5):318-322.

doi:10.1186/1479-5868-9-120

Cite this article as: Guo et al:: Differences in lifestyle behaviors, dietary habits, and familial factors among normal-weight, overweight, and obese Chinese children and adolescents. International Journal of Behavioral Nutrition and Physical Activity 2012 9:120.

\section{Submit your next manuscript to BioMed Central and take full advantage of:}

- Convenient online submission

- Thorough peer review

- No space constraints or color figure charges

- Immediate publication on acceptance

- Inclusion in PubMed, CAS, Scopus and Google Scholar

- Research which is freely available for redistribution 